LAWRENCE LIVERMORE N A T IO N A L LABORATORY
Mesocarnivore Surveys on Lawrence Livermore National Laboratory Site 300, Alameda and San Joaquin Counties, California

H. O. Clark, D. A. Smith, B. L. Cypher, P. A. Kelly, J. S. Woollett

January 18, 2005 
This document was prepared as an account of work sponsored by an agency of the United States Government. Neither the United States Government nor the University of California nor any of their employees, makes any warranty, express or implied, or assumes any legal liability or responsibility for the accuracy, completeness, or usefulness of any information, apparatus, product, or process disclosed, or represents that its use would not infringe privately owned rights. Reference herein to any specific commercial product, process, or service by trade name, trademark, manufacturer, or otherwise, does not necessarily constitute or imply its endorsement, recommendation, or favoring by the United States Government or the University of California. The views and opinions of authors expressed herein do not necessarily state or reflect those of the United States Government or the University of California, and shall not be used for advertising or product endorsement purposes.

This work was performed under the auspices of the U.S. Department of Energy by University of California, Lawrence Livermore National Laboratory under Contract W-7405-Eng-48. 


\section{Mesocarnivore Surveys on Lawrence Livermore National Laboratory Site 300 Alameda and San Joaquin Counties, California}

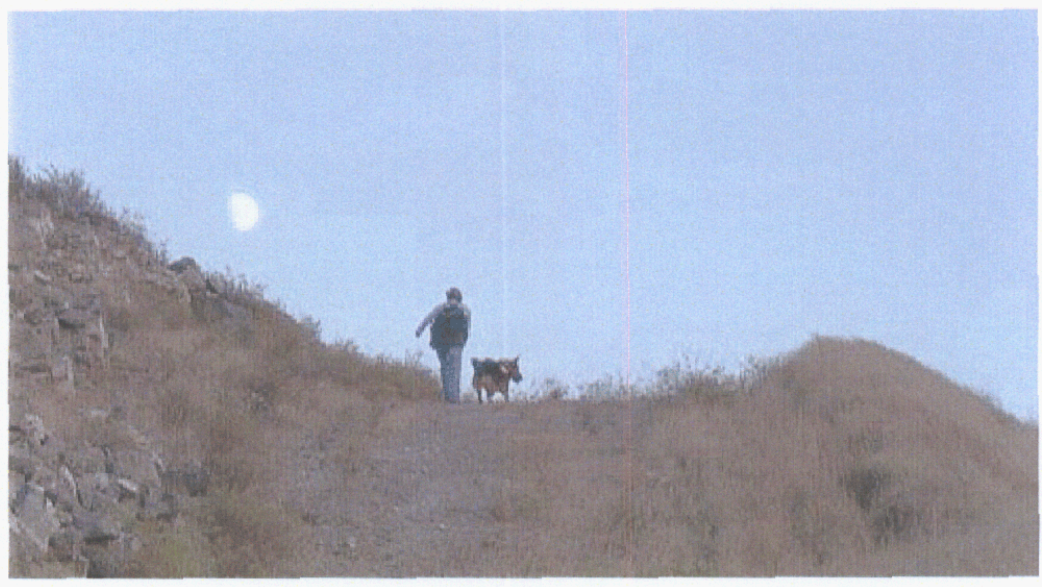

California State University, Stanislaus Endangered Species Recovery Program February 21, 2003 


\section{Mesocarnivore Surveys on Lawrence Livermore National Laboratory Site 300 Alameda and San Joaquin Counties, California}

Fulfillment of contract B527311

Prepared for:

Thom T. Kato, Mike G. van Hattem, Lisa E. Paterson, and James S. Woollett, Jr. U.S. Department of Energy - University of California Lawrence Livermore National Laboratory Site 300 7000 East Ave., Livermore, CA 94550-9234

Prepared by:

Howard O. Clark, Jr., Deborah A. Smith, Brian L. Cypher, and Patrick A. Kelly California State University, Stanislaus Endangered Species Recovery Program 1900 N Gateway Blvd., suite 101 Fresno, CA 937270-1622

File name: LLNL_ESRP_0210c.doc Mesocarnivore Surveys on Lawrence Livermore National Laboratory Site 300 Alameda and San Joaquin Counties, California 


\section{INTRODUCTION}

Lawrence Livermore National Laboratory (LLNL), operated under cooperative agreement between the University of California and the U. S. Department of Energy, administers and operates an approximately $11 \mathrm{mi} 2(28 \mathrm{~km} 2)$ test site in the remote hills at the northern end of the South Coast Ranges of Central California (Figure 1). Known as Site 300 , this expanse of rolling hills and canyons supports a diverse array of grassland communities typical of lowland central California. The facility serves a variety of functions related to testing non-nuclear explosives, lasers, and weapons subsystems. The primary purpose of this project was to determine the presence of any mesocarnivores on Site 300 that use the property for foraging, denning, and other related activities. The surveys occurred from mid-September to mid-October, 2002.

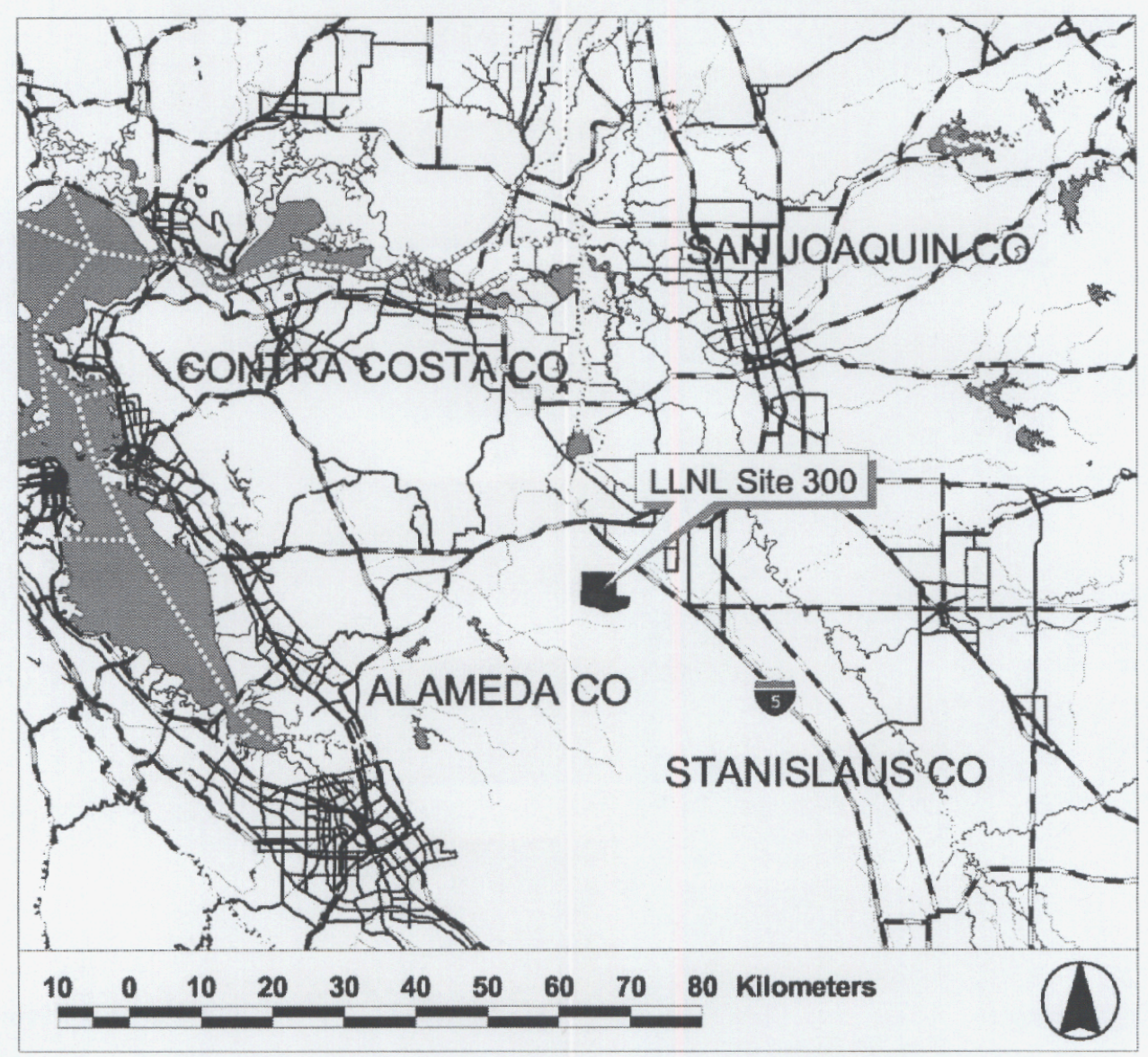

Figure 1. General vicinity map showing LLNL Site 300. 


\section{METHODS}

\section{Spotlighting}

Two or more persons, using 2 hand-held $10.8 \times 106 \mathrm{~lm} / \mathrm{m} 2$ spotlights, conducted surveys starting after sunset and lasting for 2-3 h. Survey vehicle speed was maintained between $10-15 \mathrm{mph}(16-25 \mathrm{kph})$. When eyeshine was observed, the survey vehicle was stopped and positive identification of the species was made using 7 750 binoculars (Nikon Stayfocus Plus II, Nikon, Melville, NY). The time, mileage, species, location, and activity of the observations were recorded on standard survey data sheets and sighting locations recorded with a hand-held global positioning system (GPS) unit (Garmin GPS III+, Garmin International Inc., Olathe, KS). Spotlight sessions were not conducted in areas where camera stations (see below) were operating. For each survey session (1 evening), a specific section of Site 300 was focused on rather than conducting a site-wide session.

\section{Camera Stations}

Camera stations were established at 10 locations and operated for 7 consecutive days, and then moved, for a sampling of 30 locations. The stations consisted of a Trailmaster ${ }^{\circledR}$ TM550 passive infrared trail monitor (Goodson \& Associates, Inc., Lenexa, KS) and a Canon Sure Shot A1/Prima AS-1 camera (Canon USA, Inc., Lake Success, NY). Each camera was sighted using a laser pointer and the target location was baited with scented predator survey disks (U. S. Department of Agriculture, Pocatello, ID). The trail monitors are tripped when motion is detected in the target field. When activated, a signal is sent to the camera and a picture of the target area is taken.

\section{Detection Dogs}

A specially trained scat-detection dog was used to locate feces (scats) of three fox species: kit fox (Vulpes macrotis), red fox (V. vulpes), and gray fox (Urocyon cinereoargenteus). Dogs have been used prior in wildlife research and management to locate scats of species such as black-footed ferrets (Mustela nigripes, Dean 1979, Winter 1981), wolves (Canis lupus), coyotes (C. latrans), black bears (Ursus americanus, Paquet, 1982-1989, University of Calgary, unpublished data), lynx (Lynx canadensis, Breitenmoser and Breitenmoser-Wursten, 1984-1994, IUCN/SSC Cat Specialist Group, unpublished data), and grizzly bears (U. arctos, Wasser et al., 1999-2002, University of Washington, unpublished data). Additionally, previous studies have assessed the detection and accuracy rates of dogs trained to find scats of San Joaquin kit foxes $(V . m$. mutica, Smith et al. 2001, 2002), and demonstrated that dogs provide an excellent tool for locating kit fox scats in various habitat types. The dog used during this survey was a male German Shepherd, who was trained with a combination of standard narcotic, cadaver, and search-and-rescue detection techniques to locate scent in the air and give an "alert" to the scent of a kit fox, red fox, and gray fox scats. Generally, ideal candidate dogs for air scent work are those that are selectively bred for working intentions (e.g., German 
Shepherds, Australian Shepherds, Labrador Retrievers), are capable of demonstrating consistent concentration, and are large enough to handle walking over intense terrain yet still possess a high degree of body flexibility and agility. Furthermore, appropriate candidates are obsessed with a particular toy or food, and thus, are conditioned to associate target scents with their "highly-prized" reward object. Prior to the survey period, this German Shepherd had four years experience in air scent work, and three years experience in specifically locating scats of kit fox, red fox, and gray fox.

Scat detection surveys were conducted in the evenings. The survey team consisted of a detection dog and two biologists (dog-handler and orienteer). Survey times, routes, and activities were recorded by the orienteer using a GPS unit. A digital camera (Nikon Coolpix 900, Nikon, Melville, NY) was used to document habitat conditions.

\section{RESULTS}

\section{Spotlighting}

Eight spotlighting sessions were conducted; 2 sessions per week. The average distance and range covered for each session were 19.8 miles $(31.8 \mathrm{~km})$ and 14 to 28 miles (23 to $45 \mathrm{~km}$ ), respectively. Table 1 summarizes the spotlighting results for badger (Taxidea taxus), bobcat (L. rufus), and coyote. Other species observed included burrowing owl (Athene cunicularia), great-horned owl (Bubo virginianus), barn owl (Tyto alba), common poorwill (Phalaenoptilus nuttallii), western meadowlark (Sturnella neglecta), red-tailed hawk (Buteo jamaicensis), kangaroo rat (Dipodomys heermanni), deer mouse (Peromyscus maniculatus), black-tailed hare (Lepus californicus), desert cottontail (Sylvilagus audubonii), western toad (Bufo boreas), California red-legged frog (Rana aurora draytonii), wild boar (Sus scrofa), and black-tailed deer (Odocoileus hemionus). Please see the Appendix for the spotlight routes and mesocarnivore locations.

Table 1. Summary of mesocarnivore sightings during spotlighting.

\begin{tabular}{l|ccccccccc} 
Species & 16 Sep & 17 Sep & 30 Sep & 1 Oct & 8 Oct & 9 Oct & 14 Oct & 15 Oct & Total \\
\hline Badger & - & 2 & 3 & 1 & 3 & - & 1 & - & 10 \\
Bobcat & 1 & - & - & - & - & - & - & - & 1 \\
Coyote & 1 & 2 & 3 & 2 & - & 2 & 3 & 1 & 14 \\
\hline Moon $^{1}$ & $75 \%$ & $83 \%$ & $45 \%$ & $35 \%$ & $5 \%$ & $11 \%$ & $60 \%$ & $70 \%$ &
\end{tabular}

\footnotetext{
${ }^{1}$ Fraction of the moon surface illuminated at midnight on the date of the survey (US Naval Observatory. 2002. Astronomical Applications Dept., Washington, DC).
} 


\section{Camera Stations}

Camera stations were established at 30 locations. The first 10 locations were set up for 14 days, whereas the following 2 relocations were set up for 7 days each. No one checked the cameras during the 14-day period due to scheduling conflicts, and is referred to as "Week 1" in Table 2, which summarizes the species recorded by the cameras. Please see the Appendix for camera station and wildlife locations. The cameras operated from 19:00 to 06:00 each day, but the monitor recorded trip events constantly (24-hr period). The only animal not recorded by spotlighting, but detected by the cameras, was a raven (Corvus corax).

Table 2. Summary of camera station events. Week 1 did not record any hits due to the film being spent on a sunrise activation malfunction.

\begin{tabular}{c|ccc|c} 
Species & Week 1 & Week 2 & Week 3 & Total \\
\hline Badger & 0 & 1 & 0 & 1 \\
Boar & 0 & 0 & 2 & 2 \\
Bobcat & 0 & 1 & 0 & 1 \\
Coyote & 0 & 3 & 0 & 3 \\
Deer & 0 & 1 & 6 & 7 \\
Hare & 0 & 7 & 0 & 7 \\
Raven & 0 & 1 & 0 & 1
\end{tabular}

\section{Detection Dogs}

The scat detection dog surveyed four routes, ranging from 2 to $3 \mathrm{mi}$ ( 3.0 to $4.5 \mathrm{~km}$ ) each. No fox scats were located. However, the detection dog did alert us to 2 feral dogs during a survey on 9 October. Please see the Appendix for the survey routes.

\section{DISCUSSION}

Three techniques were employed to survey for mesocarnivores at Site 300. The use of multiple techniques helps facilitate the detection of mesocarnivores as certain techniques may be more effective in detecting certain species. For example, spotlighting may be less effective in detecting smaller species, and detection dogs only were trained to detect canid scats.

The property appears to be supporting a healthy population of coyotes and badgers. On a few occasions, coyotes and badgers were spotted in the same vicinity. Several examples of cooperative interactions between badgers and coyotes have been documented (Hawkins 1907, Cahalane 1950). Kiliaan et al. (1991) reported a badger and coyote hunting together near Cypress Hills Provincial Park, Alberta, Canada. Coyote-badger interactions are not always mutually cooperative. Harassment of badgers by coyoteseven predation - has been documented (Kiliaan et al. 1991). Minta et al. (1992) showed 
that a coyote's available foraging range increased greatly while hunting with badgers. They further concluded that badger-coyote associations were probably not cooperation and not mutual consideration, as all behavior appeared to be directed towards prey capture or toleration of each other.

The 15 sightings of burrowing owls indicate that Site 300 is able to support this rare species (see the Appendix for a map of sightings). Burrowing owls were once common in California, but their populations have declined in recent years (Kaufman 2000). The species is now a State and Federal Species of Concern (California Department of Fish and Game 2002). Burrowing owls are found in open, dry grasslands, agricultural and range lands, and desert communities often associated with burrowing and fossorial animals. Burrowing owls have been known to use burrows excavated by badgers, ground squirrels, and prairie dogs (Butts and Lewis 1982, Plumpton and Lutz 1993).

The camera stations and spotlight sessions were effective in detecting the presence of mesocarnivores. Both methods confirmed the presence of bobcat-a predator that is usually rather difficult to observe. Orloff (1986) detected gray foxes on Site 300, however, during this study, no foxes were detected. We did not confirm the presence of four other mesocarnivores that were documented by Orloff in 1986: raccoon (Procyon lotor), long-tailed weasel (M. frenata), striped skunk (Mephitis mephitis), and western spotted skunk (Spilogale gracilis). It is not known if ecological conditions on Site 300 have changed over the past 16 years (e.g., changes in prey base, vegetation, rainfall, etc.) favoring the presence of some mesocarnivores, but not others.

We feel that the survey techniques employed were effective in detecting mesocarnivores on Site 300 . However, our effort was relatively short-term. It is possible that additional species may be present in low densities making detection difficult.

\section{ACKNOWLEDGEMENTS}

We thank Jim Woollett (Biologist at LLNL Site 300) for assisting us in the field while collecting data, spotlighting, and setting/retrieving the camera stations. Site 300 staff also provided us with a spotlight vehicle. We thank the security personnel and the badge office personnel for their perseverance in safety and aiding us in making our stay productive, safe, and enjoyable. 


\section{LITERATURE CITED}

Butts, K. O. and J. C. Lewis. 1982. The importance of prairie dog towns to burrowing owls in Oklahoma. Proceedings of the Oklahoma Academy of Science 62:46-52.

Cahalane, V.H. 1950. Badger-Coyote "Partnerships". Journal of Mammalogy 31:354355 .

California Department of Fish and Game. 2002. Wildlife and habitat Data Analysis Branch. Natural Diversity Data Base.

Dean, E. E. 1979. Nongame Wildlife Studies: Training of dogs to detect black-footed ferrets. N.M. Dept. of Game and Fish; Project No.: N.M. FW-017-R-07. 13 pp.

Hawkins, A.H. 1907. Coyote and badger. The Ottawa Naturalist 21:37.

Kaufman, K. 2000. Birds of North America. Houghton Mifflin Co. New York, New York. 384 pp.

Kiliaan, H.P.L., C. Mamo, and P. C. Paquet. 1991. A coyote, Canis latrans, and badger, Taxidea taxus, interaction near Cypress Hills Provincial Park, Alberta. The Canadian Field-Naturalist 105:122-123.

Minta, S.C., K. A. Minta, and D. F. Lott. 1992. Hunting associations between badgers (Taxidea taxus) and coyotes (Canis latrans). Journal of Mammalogy 73:814-820.

Orloff, S. 1986. Wildlife Studies of Site 300 Emphasizing Rare and Endangered Species, Lawrence Livermore National Laboratory, San Joaquin County, California. BioSystems Analysis, Inc., Sausalito, California. 46 pp. + appendices.

Plumpton, D., and R. S. Lutz. 1993. Nest site selection by Burrowing Owls in Colorado. Journal of Raptor Research 27:175-179.

Smith, D. A., K. Ralls, B. Davenport, B. Adams, and J. E. Maldonado. 2001. Canine Assistants for Conservationists. Science 291:435.

Smith, D. A., K. Ralls, A. Hurt, B. Adams, M. Parker, B. Davenport, M. C. Smith, and J. E. Maldonado. 2002. Detection and accuracy rates of dogs trained to find scats of San Joaquin kit foxes (Vulpes macrotis mutica). Animal Conservation. Submitted.

Winter, W. 1981. Black-footed ferret search dogs. Santa Fe, NM: Southwestern Research Institute. 9 pp. 


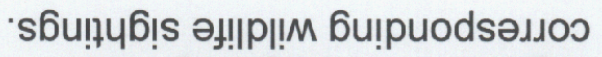

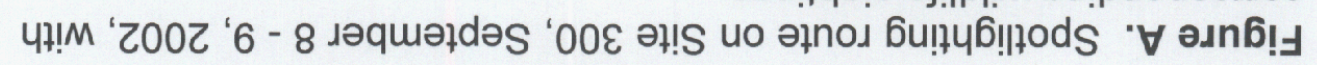

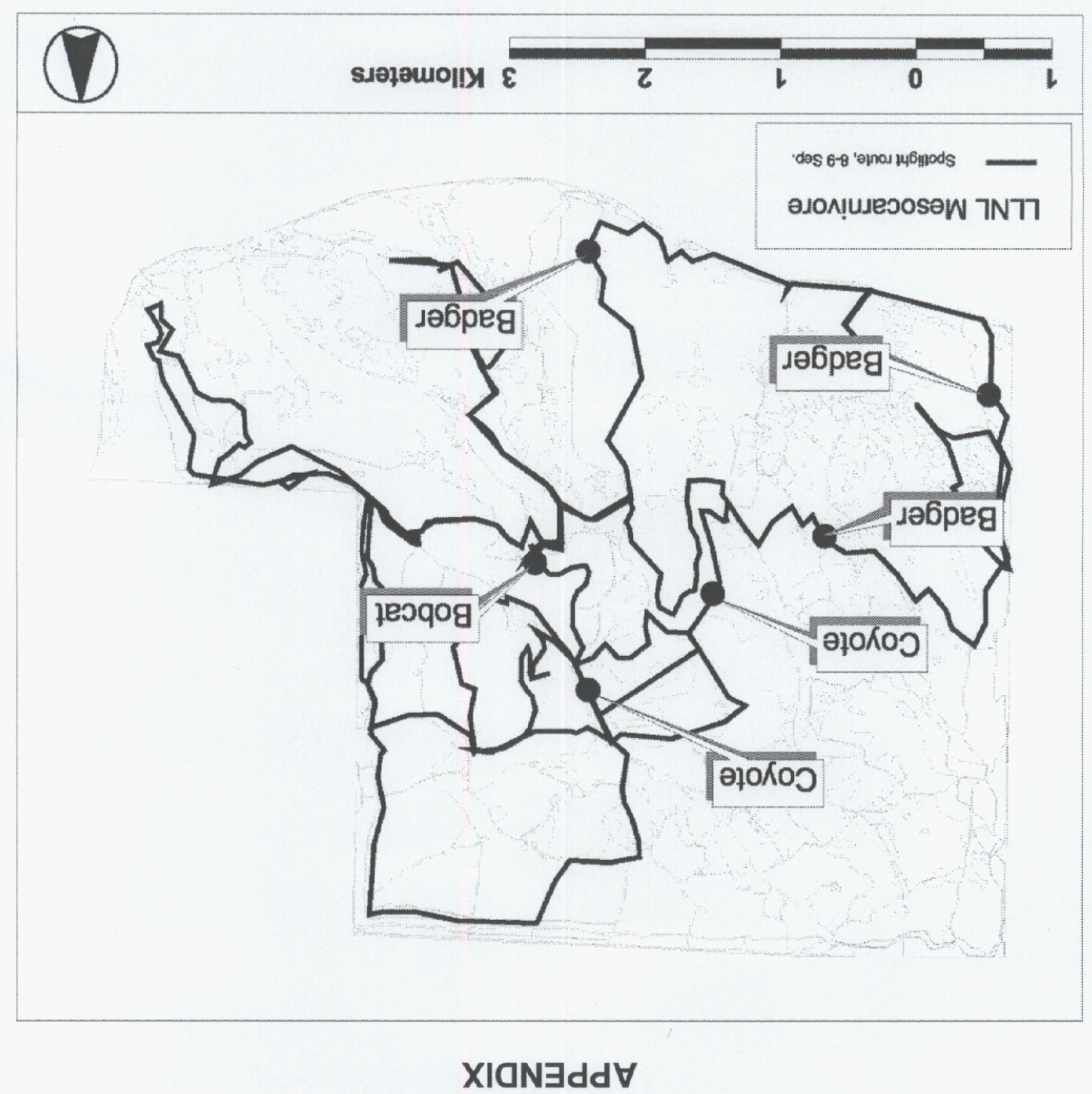




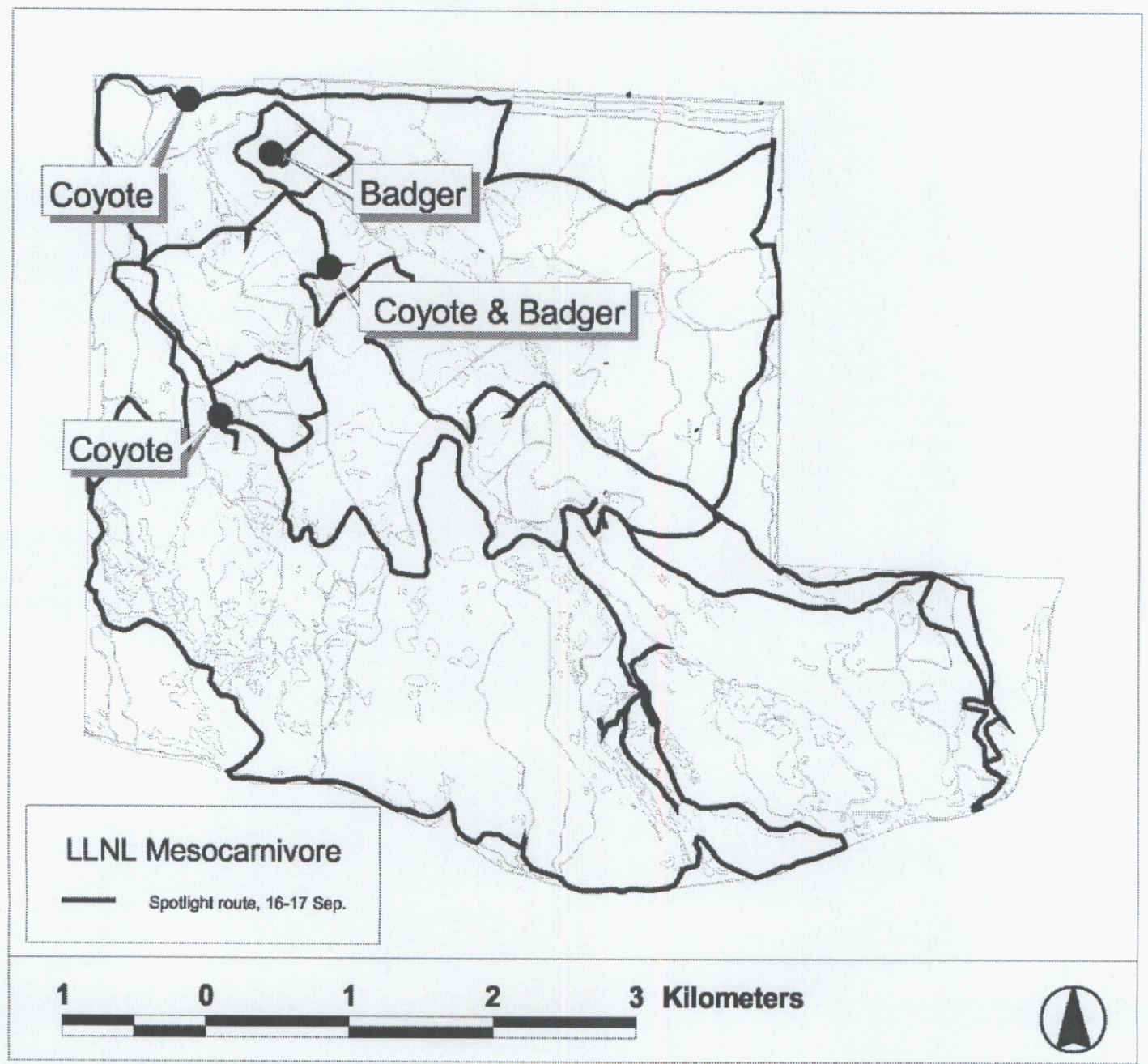

Figure B. Spotlighting route on Site 300, September 16 - 17, 2002, with corresponding wildlife sightings. 


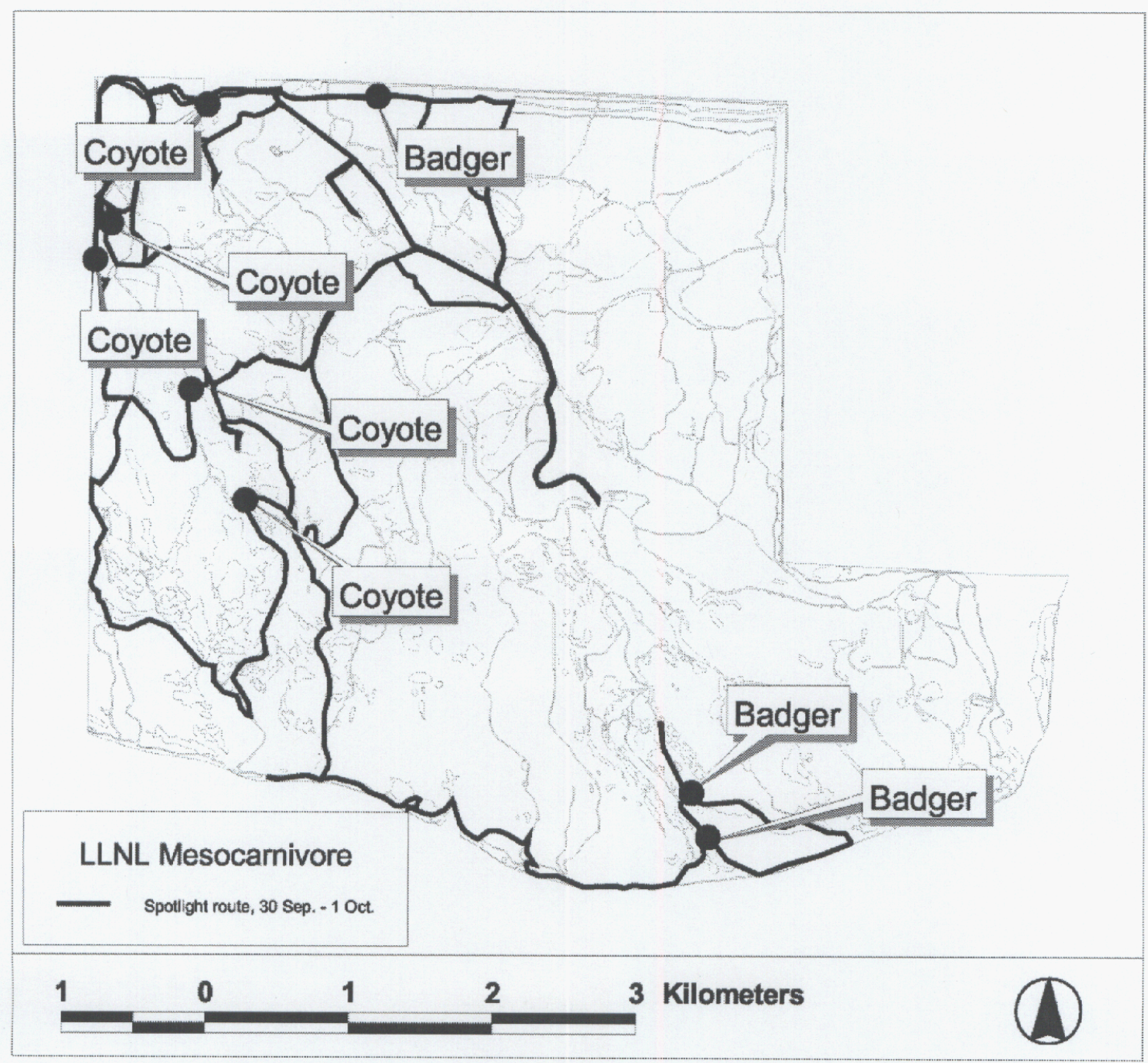

Figure C. Spotlighting route on Site 300, September 30 - October 1, 2002, with corresponding wildlife sightings. 


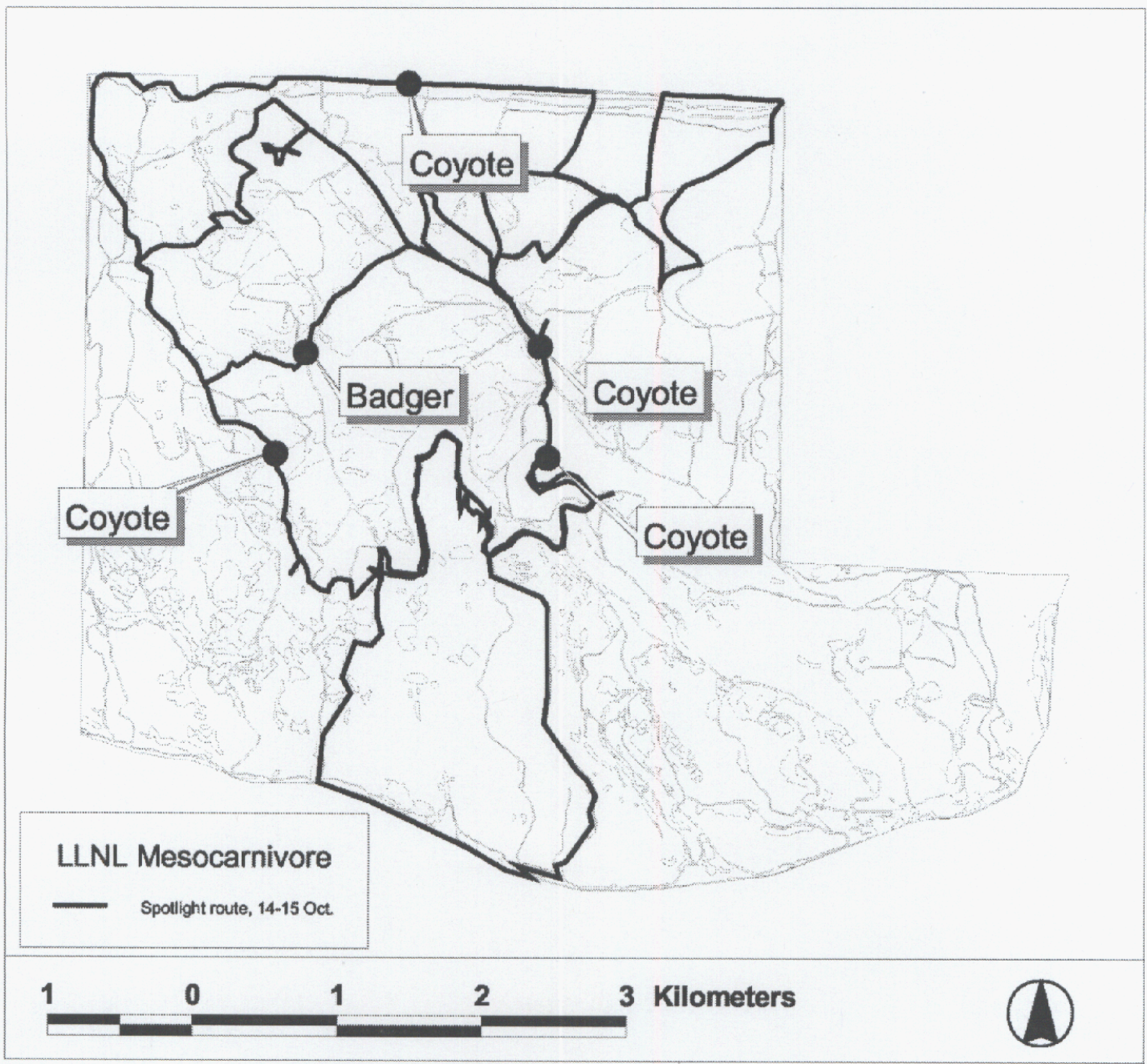

Figure D. Spotlighting route on Site 300, October 14 - 15, 2002, with corresponding wildlife sightings. 


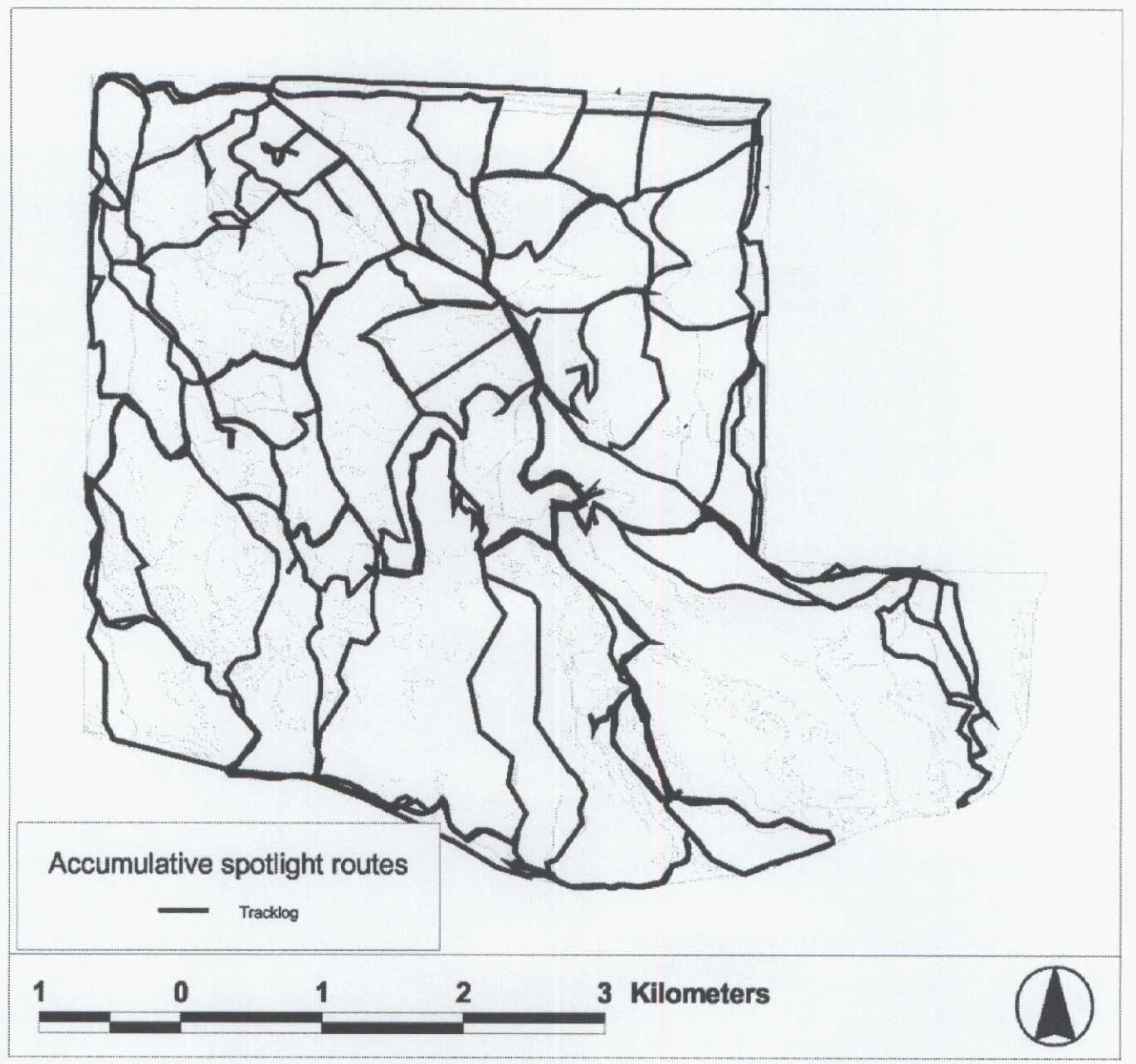

Figure E. All 8 spotlight routes combined. 


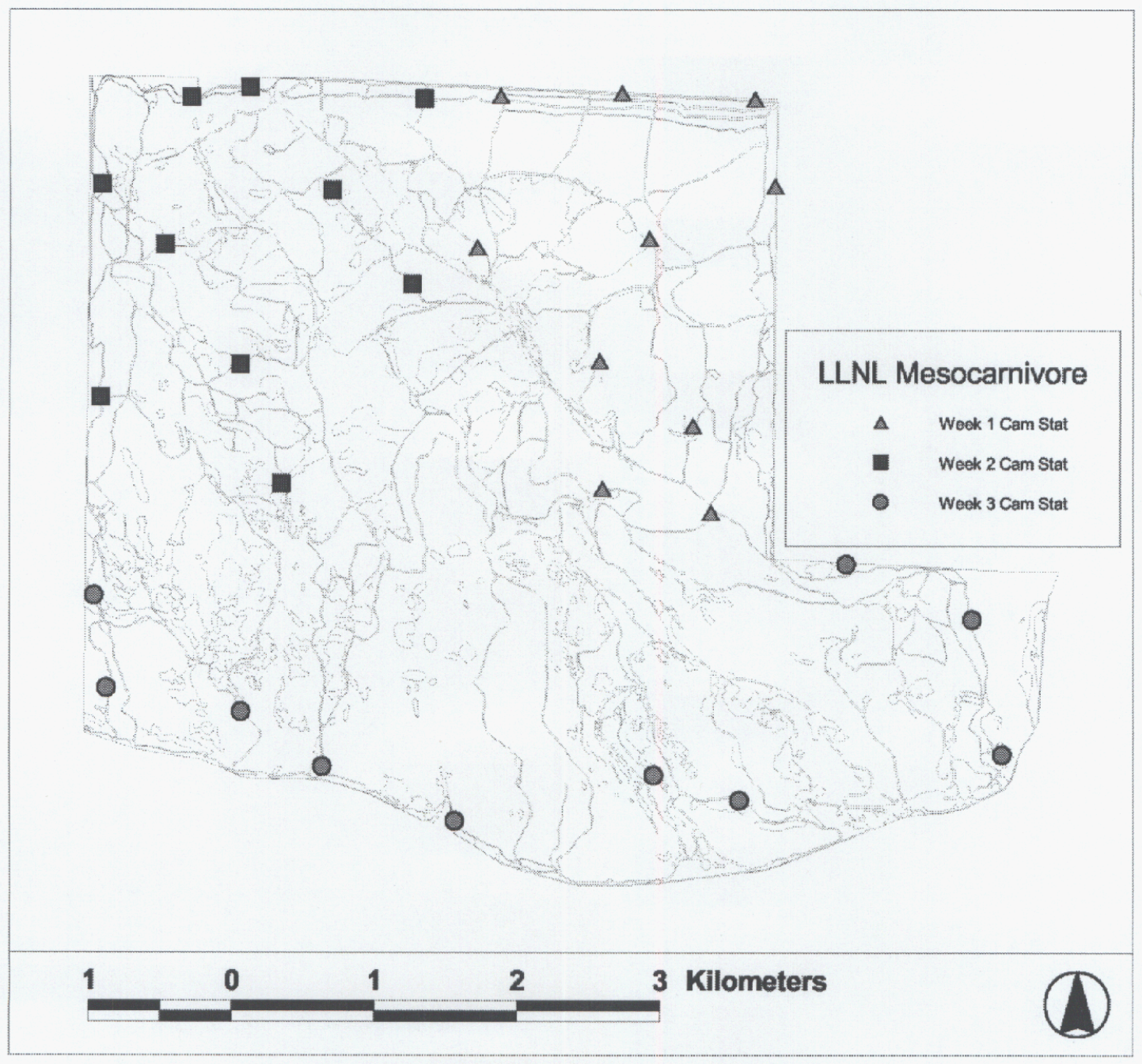

Figure F. Camera station locations on Site 300. 


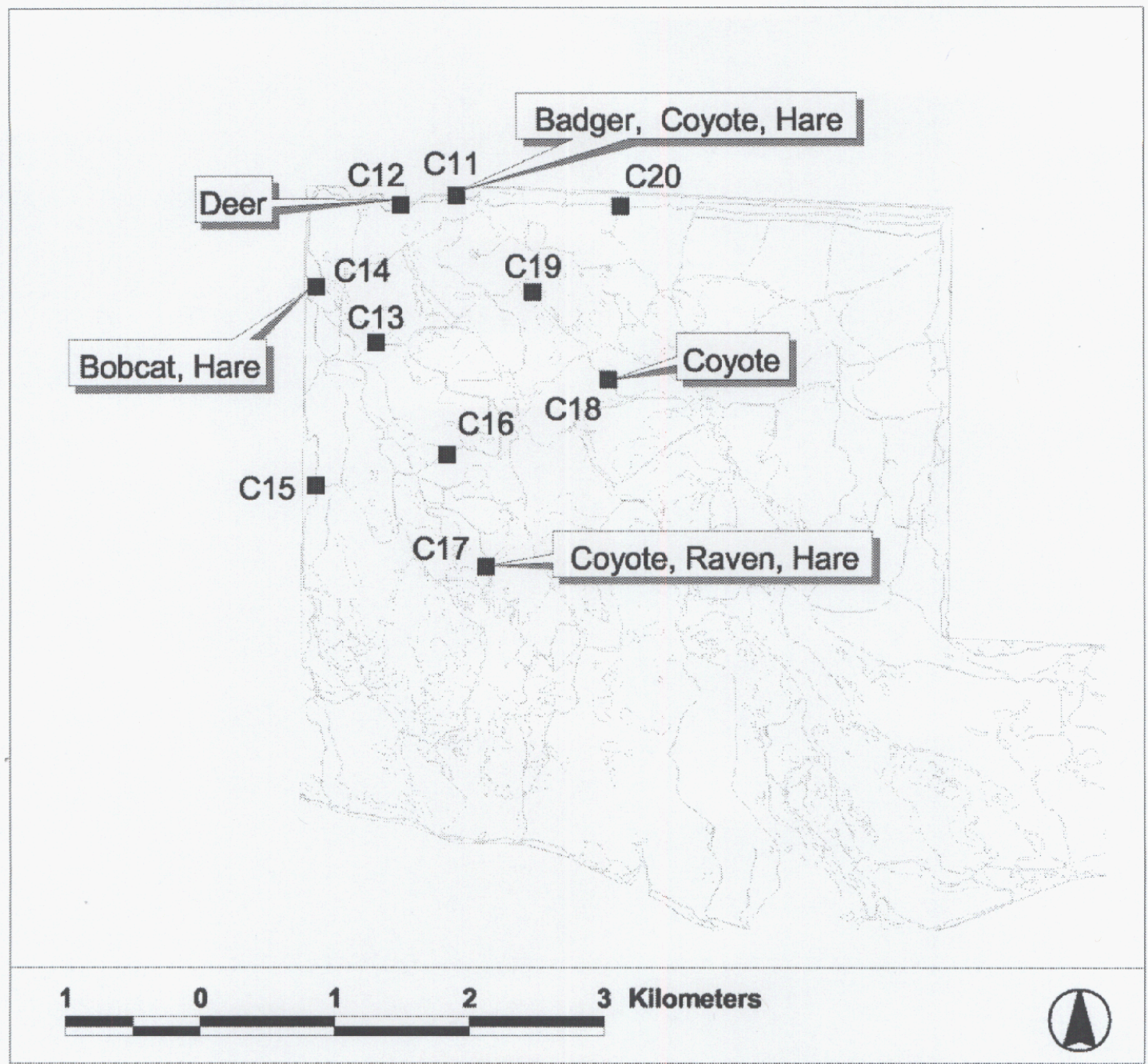

Figure G. Camera station locations for October 1 - 8, 2002, with corresponding wildlife events. 


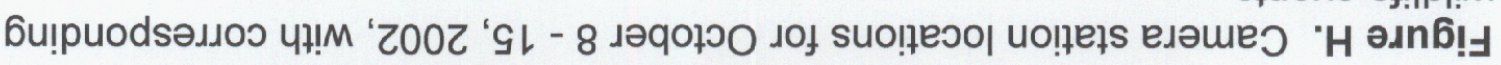

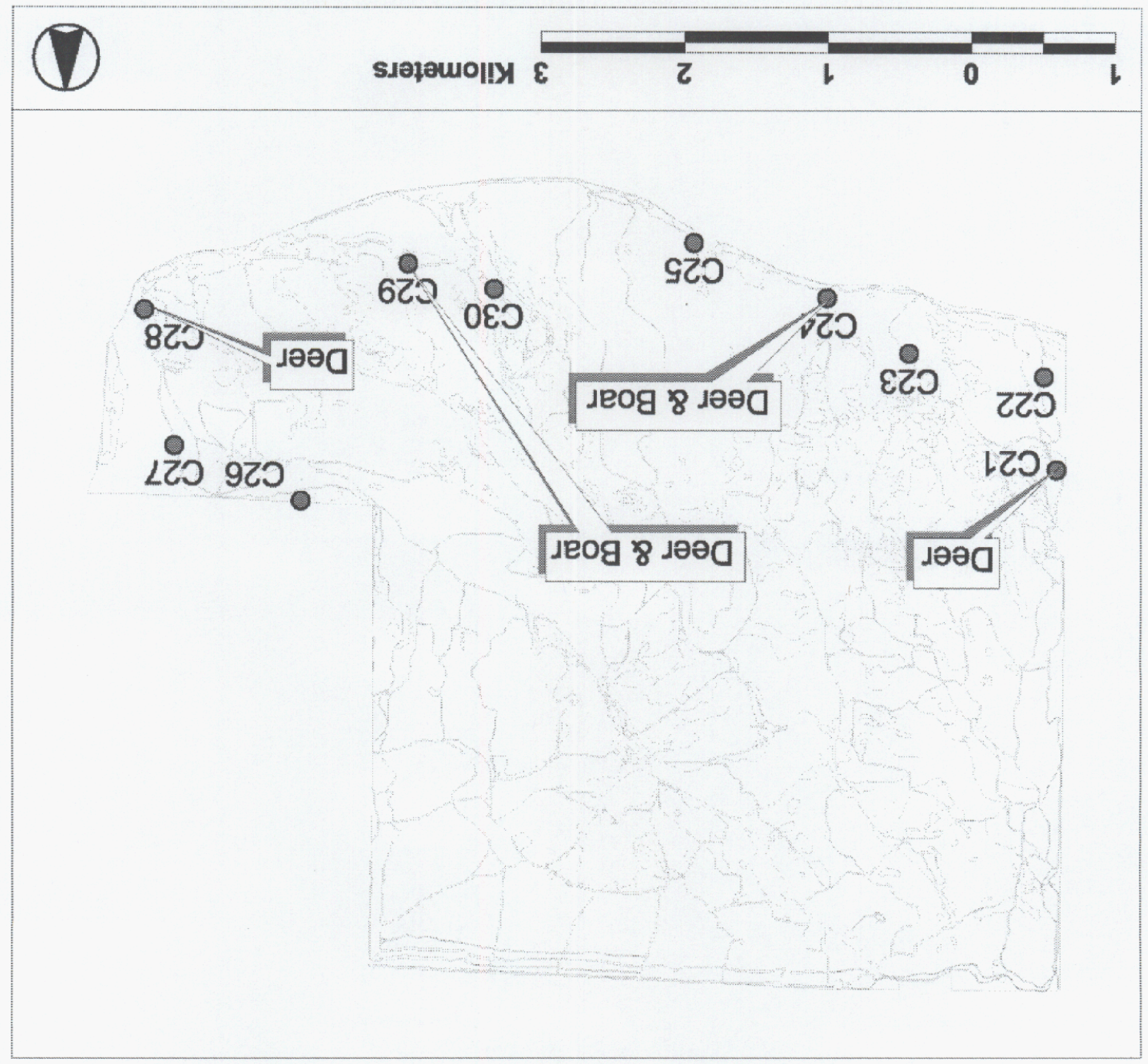




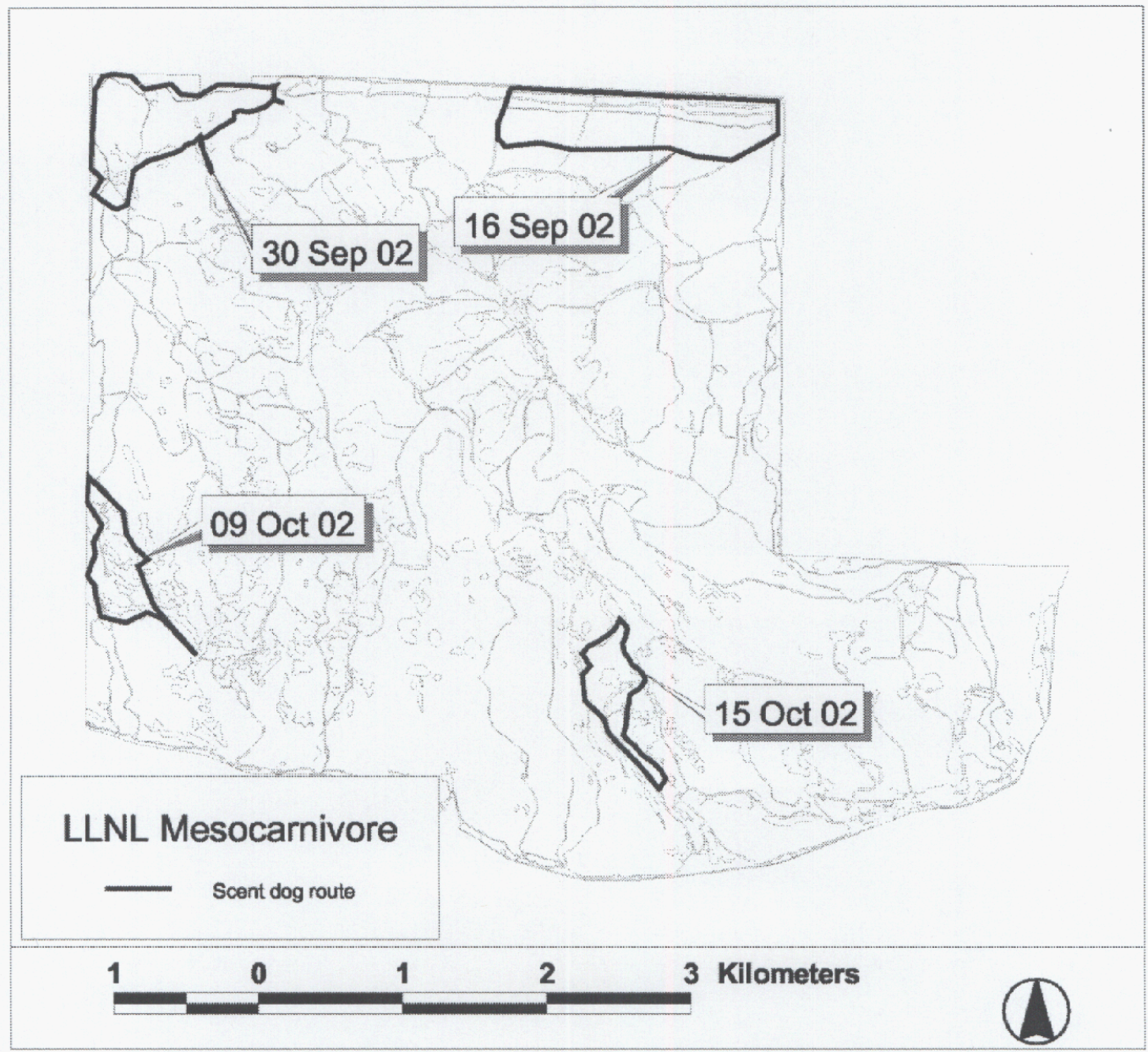

Figure I. Detection dog survey routes for fox species. 


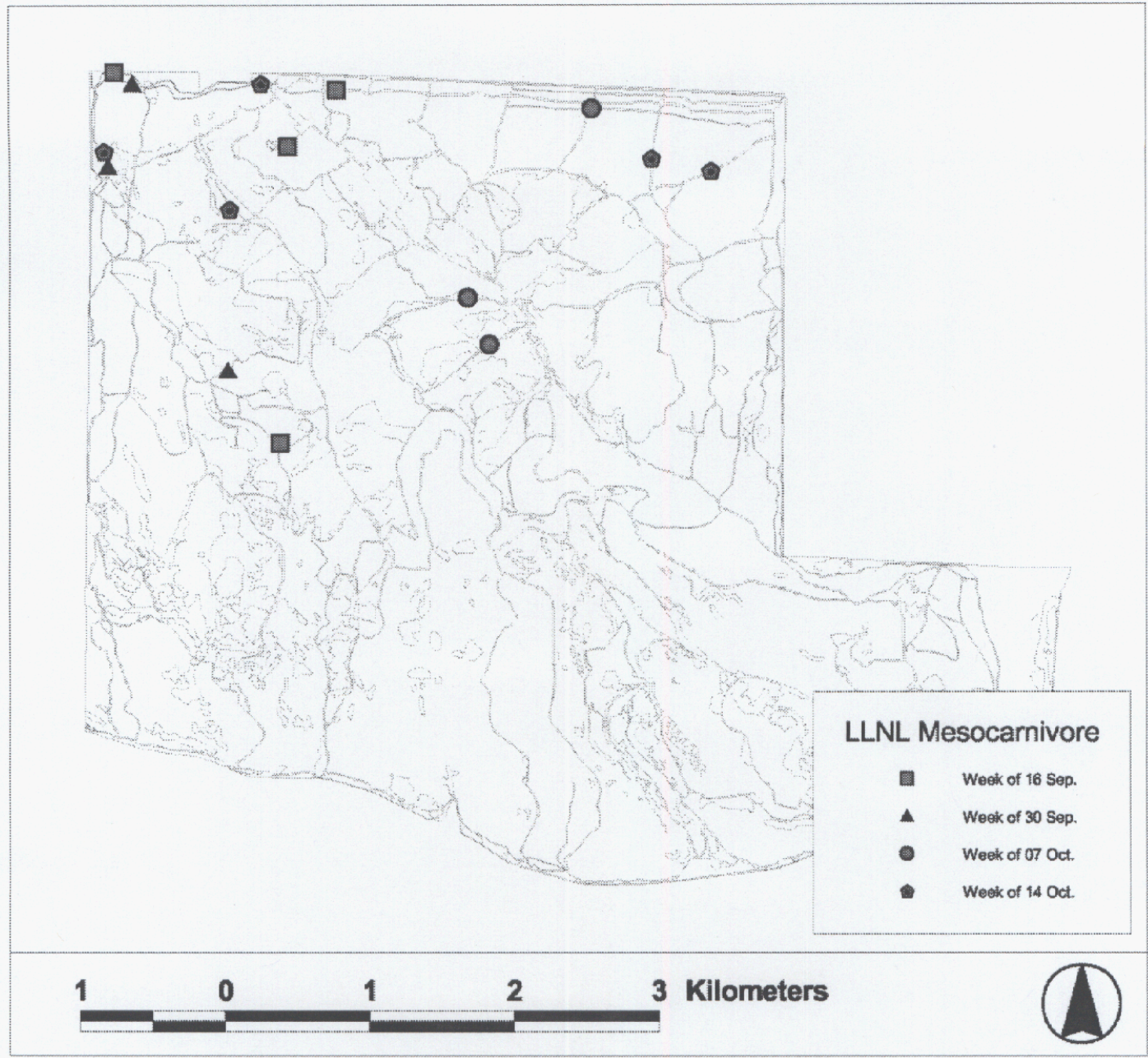

Figure J. Burrowing Owl locations, GPSed during spotlight surveys. 